\title{
BMJ Open Chronic breathlessness and sleep problems: a population-based survey
}

\author{
David C Currow (D) , ${ }^{1,2}$ Sungwon Chang, ${ }^{1}$ Diana Ferreira (D) , ${ }^{3}$ Danny J Eckert (D) ${ }^{3}$ \\ David Gonzalez-Chica (D) , ${ }^{4}$ Nigel Stocks (D) , ${ }^{4}$ Magnus Per Ekström ${ }^{5}$
}

To cite: Currow DC, Chang S, Ferreira D, et al. Chronic breathlessness and sleep problems: a populationbased survey. BMJ Open 2021;11:e046425. doi:10.1136/ bmjopen-2020-046425

- Prepublication history and additional supplemental material for this paper are available online. To view these files, please visit the journal online. (http://dx.doi.org/10.1136/ bmjopen-2020-046425).

Received 01 November 2020 Accepted 22 July 2021

Check for updates

(c) Author(s) (or their employer(s)) 2021. Re-use permitted under CC BY-NC. No commercial re-use. See rights and permissions. Published by BMJ.

${ }^{1}$ MPACCT, Faculty of Health, University of Technology Sydney, Sydney, New South Wales, Australia

${ }^{2}$ Wolfson Palliative Care Research Centre, University of Hull, Hull, England

${ }^{3}$ College of Medicine and Public Health, Flinders University, Bedford Park, South Australia, Australia

${ }^{4}$ University of Adelaide, Adelaide, South Australia, Australia

${ }^{5}$ Department of Clinical

Sciences, Division of Respiratory Medicine \& Allergology, Lund University, Lund, Sweden

Correspondence to

Dr David C Currow;

David.Currow@uts.edu.au

\section{ABSTRACT}

Objectives This study aimed to explore the relationship (presence and severity) between chronic breathlessness and sleep problems, independently of diagnoses and health service contact by surveying a large, representative sample of the general population.

Setting Analysis of the 2017 South Australian Health Omnibus Survey, an annual, cross-sectional, face-to-face, multistage, clustered area systematic sampling survey carried out in Spring 2017.

Chronic breathlessness was self-reported using the ordinal modified Medical Research Council (mMRC; scores 0 (none) to 4 (housebound)) where breathlessness has been present for more than 3 of the previous 6 months. 'Sleep problems-ever' and 'sleep problem-current' were assessed dichotomously. Regression models were adjusted for age; sex and body mass index (BMI). Results 2900 responses were available (mean age 48.2 years $(S D=18.6) ; 51 \%$ were female; mean $B M I$ $27.1(S D=5.9))$. Prevalence was: $2.7 \%(n=78)$ sleep problems-past; $6.8 \%(n=198)$ sleep problems—current and breathlessness (mMRC 1-4) was $8.8 \%(n=254)$. Respondents with sleep problemspast were more likely to be breathless, older with a higher BMI and sleep problems - present also included a higher likelihood of being female.

After adjusting for age, sex and BMI, respondents with chronic breathlessness had $1.9(95 \% \mathrm{Cl}=1.0$ to 3.5$)$ times the odds of sleep problems - past and sleep problemscurrent (adjusted $\mathrm{OR}=2.3 ; 95 \% \mathrm{Cl}=1.6$ to 3.3 ).

Conclusions There is a strong association between the two prevalent conditions. Future work will seek to understand if there is a causal relationship using validated sleep assessment tools and whether better managing one condition improves the other.

\section{INTRODUCTION}

Chronic breathlessness is highly prevalent. It affects up to $8 \%$ of the adult population in high-income countries ${ }^{1-3}$ and is associated with impaired physical and mental quality of life, ${ }^{4}$ increased levels of anxiety and depression, ${ }^{5}$ decreased levels of sexual activity in the elderly, ${ }^{6}$ increased social isolation ${ }^{78}$ and poorer prognosis. ${ }^{910}$ Unlike many symptoms, chronic breathlessness often worsens late in life. $^{11}$

Similarly, impaired sleep quality and insomnia are prevalent across the community,

\section{Strengths and limitations of this study}

This was a large, random survey of the population using trained interviewers in face-to-face interviews, irrespective of health service contact.

- The survey used tools that were designed for population survey use.

- This study can only reflect associations, not cause and effect.

- The data on chronic breathlessness and sleep problems were based on self-report, not clinical assessments.

The data are cross-sectional, not longitudinal.

even in the absence of obstructive sleep apnoea (OSA). ${ }^{12-14} \mathrm{Up}$ to $40 \%$ of people with OSA will also have symptomatic insomnia. ${ }^{15}$ Poor sleep quality and insomnia are associated with worse physical and mental quality of life, ${ }^{16}$ anxiety and depression, ${ }^{17-19}$ less satisfaction with sexual function in postmenopausal women ${ }^{1920}$ and poorer life expectancy. ${ }^{21}$ Both chronic breathlessness and poor sleep quality are more common in the elderly. ${ }^{413}$

Associations in the general population, without relying on contact with health services, between chronic breathlessness (irrespective of the underlying aetiologies) and sleep problems have not been defined. Understanding this relationship is important given the high burden of these conditions, the complex relationship between them and the ability to explore changing the symptomatic course of both by ameliorating either one of them.

By asking a broad sample of randomly selected members of the public about their chronic breathlessness and sleep problems, key clinical and demographic factors can be defined for the first time. Further, if there is a relationship between worsening chronic breathlessness and the presence of sleep problems, intervention studies to improve sleep may be beneficial in the management of chronic breathlessness and vice versa. 
The aim of this study was to evaluate the association between the presence and severity of chronic breathlessness and self-reported sleep problems.

\section{METHODS}

\section{Survey design}

This was an analysis of the 2017 South Australian Health Omnibus Survey (online supplemental appendix 1), ${ }^{3} 22$ an annual, cross-sectional, face-to-face, multistage, clustered area systematic sampling survey. It was run by a commercial research organisation, providing deidentified data for user-pays researchers. Approximately 200 questions (including different questions on symptoms, self-reported conditions and health service utilisation) were asked annually. Each year, demographic questions remained relatively unchanged.

Data were collected through interviews in participants' homes by trained interviewers, lasting 60-90 min. Members of the public were therefore engaged, independently of health service contact. The methodology has been described previously in detail. ${ }^{22} 23$

\section{Setting and participants}

South Australia is the second smallest state by population in Australia, with a population of approximately 1.73 million people (6.9\% of the Australian population), mostly living in Adelaide, the state's capital. ${ }^{24}$ The survey was carried out between September and December each year having been piloted with 50 residents from the general community annually. A stratified sampling method identified a representative cohort from metropolitan and rural towns with populations of more than 1000. More than 5000 properties were approached annually.

Two randomisations occurred during the sampling process: (1) by census collector districts (CCDs) and (2) starting points within each randomly selected CCDs. From the starting point in each CCD, a skip pattern of every tenth property was used to select the next property. Properties approached included houses, businesses, properties with other uses or vacant land. Hotels, hospitals, caravan parks and aged care facilities were not sampled. When houses were identified, interviewers would return up to six times if contact could not be made with the household initially. Participation rates were calculated on the number of potential participants with whom any contact was made.

One interview was conducted in each household with the person aged $\geq 15$ years who most recently had a birthday. If that person was unwilling to participate and another member of the household was unable to replace him/her, then that household was classified as declining participation.

\section{Data quality}

All data were double entered, with a supervisor following up missing responses by telephone. Additionally, $10 \%$ of each interviewer's respondents were recontacted to confirm their eligibility and ensure consistency of responses by reanswering a selection of questions. Data were anonymised and then released to researchers for analysis.

An initial total of 2977 people were engaged with the interviews with an overall participation rate of $65.3 \%$, of whom 2900 were 18 years or older and were included in the analysis. All eligible respondents were included to maximise power and minimise bias. For the purposes of this study, analyses were restricted to participants 18 years and older who answered questions related to breathlessness and sleep problems $(n=2900)$. As the rate of missing data was low for all variables except body mass index (BMI; 5.9\%), no data were imputed.

\section{Exposure variable}

Breathlessness was self-reported using the modified Medical Research Council (mMRC) ${ }^{25}$ Scale to the question 'thinking back over the last 6 months, have you had an episode of breathlessness that has lasted more than 3 months'. This timeframe was an arbitrary period used in previous population studies to assess a degree of chronicity. ${ }^{11}$ Response categories included $0=$ None; $1=$ 'I get short of breath when hurrying on the level or up a slight hill'; $2=$ 'I have to stop for breath when walking at my own pace on the level'; $3=$ =I stop for breath after walking 100 meters or after a few minutes on the level' or $4=$ 'I am too breathless to leave the house'. mMRC is reliable, valid and the most commonly used scale for categorising the functional impact and disability from breathlessness in daily life. ${ }^{26}{ }^{27}$ For the purpose of analysis, breathlessness was defined as an $m M R C \geq 1$. Additional analyses were undertaken to examine the severity of breathlessness using all mMRC categories (0-4) as an ordinal scale.

\section{Outcome}

'Sleep problems-ever' was assessed with the item (yes/ no): 'Has a doctor ever told you that you had insomnia or some sleep problem?' Two questions 'Are you currently taking medication for insomnia or some sleep problem?' and 'Have you seen a doctor in the last 6 months for insomnia or some sleep problem?' were combined to assess 'sleep problems-current' with 'yes' to either coding as a positive response. The study reports sleep problems-past by subtracting sleep problems-current from sleep problems-ever.

\section{Measures}

Sociodemographic data were collected on age, sex, rurality (metropolitan, non-metropolitan), country of birth (Australia, UK/Ireland, other), marital status (married/ de facto, separated/divorced, widowed, never married), highest level of educational attainment (secondary, trade/apprenticeship/certificate/diploma, degree or higher) and postcode. The postcodes were linked to the Socio-Economic Index for Areas (SEIFA). SEIFA is used to rank areas according to socioeconomic advantage/ disadvantage (eg, wealth, occupation and education) derived 
Table 1 Demographic and clinical baseline data for respondents to the 2017 South Australian Health Omnibus Survey by response to past and current sleep problems (weighted total=2900)

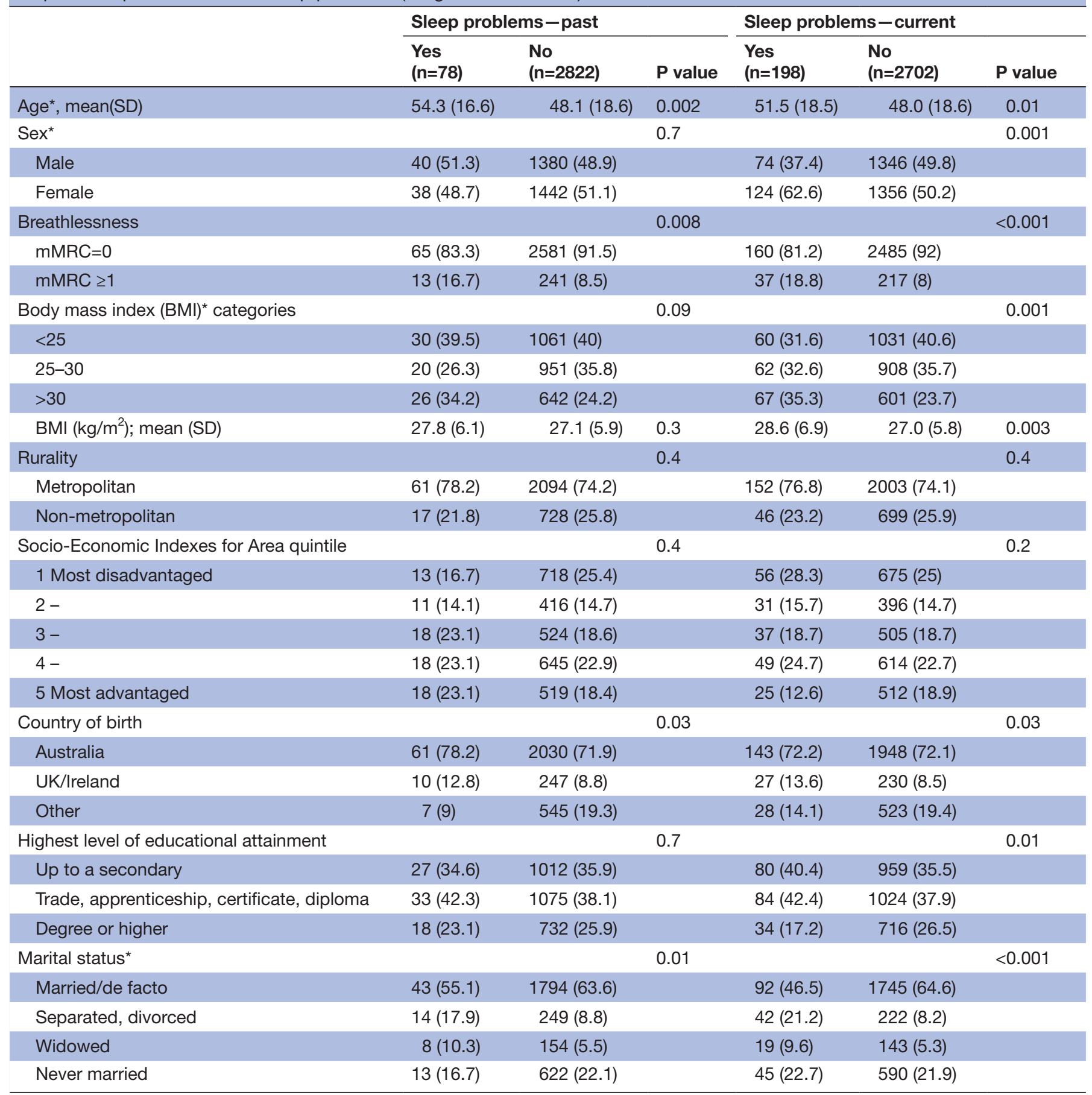

${ }^{*}$ Missing values.

mMRC, Modified Medical Research Council Scale.

from Australian national census data. ${ }^{28}$ For the purpose of this study, SEIFA was based on ranking derived from 2016 census data and was categorised into a quintiles. BMI $\left(\mathrm{kg} / \mathrm{m}^{2}\right)$ was calculated from self-reported height and weight. In addition to including BMI as a continuous measure, it was categorised according to international criteria-underweight/normal: $\leq 24.9$, overweight: 25.0 29.9 and obese: $\geq 30.0 .^{29}$

\section{Statistical analysis}

Data were weighted to the 2016 Estimated Residential Population for South Australia by 5-year age groups, sex, rurality and household size derived from the Australian census conducted that year.

Data analyses were conducted using SPSS for Windows V.26.0. (2011). Respondents' demographic characteristics were tabulated by sleep problems-ever. Bivariate 
Table 2 OR and adjusted OR of sleep problems - ever and sleep problems - current by level of chronic breathlessness (mMRC; 0-4) in an unweighted population $(n=2900)$

\begin{tabular}{lll}
\hline $\begin{array}{l}\text { Self-reported } \\
\text { exertion before } \\
\text { breathlessness } \\
\text { supervenes }\end{array}$ & \multicolumn{2}{c}{ Sleep problems } \\
\cline { 2 - 3 } & OR $(95 \% \mathrm{Cl})$ & aOR $^{\star}(95 \% \mathrm{Cl})$ \\
\hline $\begin{array}{l}\text { Past } \\
\mathrm{mMRC}=0\end{array}$ & Reference \\
$\mathrm{mMRC} \geq 1$ & $2.3(1.3$ to 4.1$)$ & $1.9(1.0$ to 3.5$)$ \\
\hline $\begin{array}{l}\text { Current } \\
\mathrm{mMRC}=0\end{array}$ & Reference \\
\hline $\mathrm{mMRC} \geq 1$ & $2.7(1.9$ to 3.8$)$ & $2.3(1.6$ to 3.3$)$ \\
\hline
\end{tabular}

*Having adjusted for age (years), sex and body mass index (kg/ $\mathrm{m}^{2}$ ).

mMRC, modified Medical Research Council Scale.

associations of 'sleep problems-ever' with sociodemographic factors were analysed using Pearson's $\chi^{2}$ tests for categorical variables and for continuous data independent sample t-tests.

The association between chronic breathlessness and sleep problem indicators was analysed using multiple logistic regression, adjusted for the potential confounders age, sex and BMI. Variables to adjust for were selected based on subject matter knowledge and the literature. ${ }^{30}$ Age and BMI were included as continuous variables and the assumption of linearity in their logits was assessed using Box Tidwell Test. ${ }^{31}$ The two-way interaction terms were also assessed for significance. The goodness of fit was evaluated using the Hosmer-Lemeshow Test. Associations were expressed as OR with 95\% CI. The MantelHaenszel linear-by-linear association $\chi^{2}$ test was used to detect the linear trend between severity of breathlessness (mMRC 0-4) and sleep problem indicators. $\mathrm{P} \leq 0.05$ was considered statistically significant. A sensitivity analysis using unweighted data was performed to evaluate the robustness of the findings.

\section{Ethics approval, consent and reporting}

The study was approved annually by the Human Research Ethics Committee of the South Australian Department of Health and the University of Adelaide Human Research Ethics Committee (H-097-2010). Informed verbal consent was obtained from each participant and continued participation accepted as ongoing consent. The study is reported in compliance with the STROBE checklist for cross-sectional studies. ${ }^{32}$

\section{RESULTS}

Initially, 2977 people were engaged with the interviews with an overall participation rate of $65.3 \%$, of whom 2900 were 18 years or older and answered the key questions on breathlessness and sleep. In the total respondent sample, the mean age was 48.2 years $(\mathrm{SD}=18.6)$ and $51 \%$ $(\mathrm{n}=1480)$ were females. Mean BMI was 27. $1 \quad(\mathrm{SD}=5.9)$. The prevalence was $2.7 \%(\mathrm{n}=78)$ for sleep problemspast and $6.8 \%(\mathrm{n}=198)$ for sleep problems-current. The overall prevalence of breathlessness (mMRC 1-4) was $8.8 \%(\mathrm{n}=254)$. Respondents with sleep problems-past were more likely to be breathless, older and with a higher BMI. Respondents with sleep problems-current were also more likely to be female. These factors were taken into the regression models. (table 1)

After adjusting for age, sex and BMI, breathlessness was strongly associated with sleep problems-past and also sleep problems-current. Respondents with chronic breathlessness had $1.9(95 \% \mathrm{CI}=1.0$ to 3.5 ; table 2$)$ times the odds of sleep problems-past than those without breathlessness. The association between breathlessness and sleep problems-current was similar (adjusted $\mathrm{OR}=2.3 ; 95 \% \mathrm{CI}=1.6$ to 3.3 ; table 2 ). No interaction terms were significant in the adjusted analysis.

Mantel-Haenszel $\chi^{2}$ tests demonstrated significant linear-by-linear associations between chronic breathlessness (mMRC 0-4) and sleep problems-past $(p<0.001)$ and sleep problems-current $(\mathrm{p}<0.001)$. The prevalence of sleep problems-ever or current generally increased with severity of breathlessness as measured with mMRC (0-4; figure 1).

The sensitivity analysis of the unweighted data demonstrated similar associations between breathlessness and sleep problems, supporting the robustness of the models.

\section{DISCUSSION}

In a random adult population sample, this study found a strong association between the presence of chronic breathlessness and insomnia or sleep problems. These findings complement previous findings that have sampled specific disease states that may be associated with chronic breathlessness such as chronic obstructive pulmonary disease (COPD), interstitial lung disease or cardiac failure. ${ }^{33}$

Two in three people responding to Omnibus surveys who identified symptomatic chronic breathlessness identified respiratory causes for their chronic breathlessness. ${ }^{33}$ Sleep problems and breathlessness are both prevalent in people with COPD, with both problems impacting on quality of life. ${ }^{34-39}$ One study of 51 patients with COPD found no relationship between sleep measures (Pittsburgh Sleep Quality Index (PSQI), Epworth Sleepiness Scale) polygraphic sleep studies and mMRC breathlessness scales. ${ }^{36}$ Another study of 130 people with COPD sought to generate symptom clusters, one of which was sleep disturbance and fatigue. ${ }^{37}$ In another case series of 60 patients with COPD, poor sleep quality and impaired health-related quality of life were highly correlated and in the regression analysis, sleep quality was the strongest predictor of quality of life. ${ }^{40}$

Other causes of chronic breathlessness include malignancy. In 128 people with advanced lung cancer, there was a strong correlation between the severity of respiratory symptoms and the likelihood of sleep 


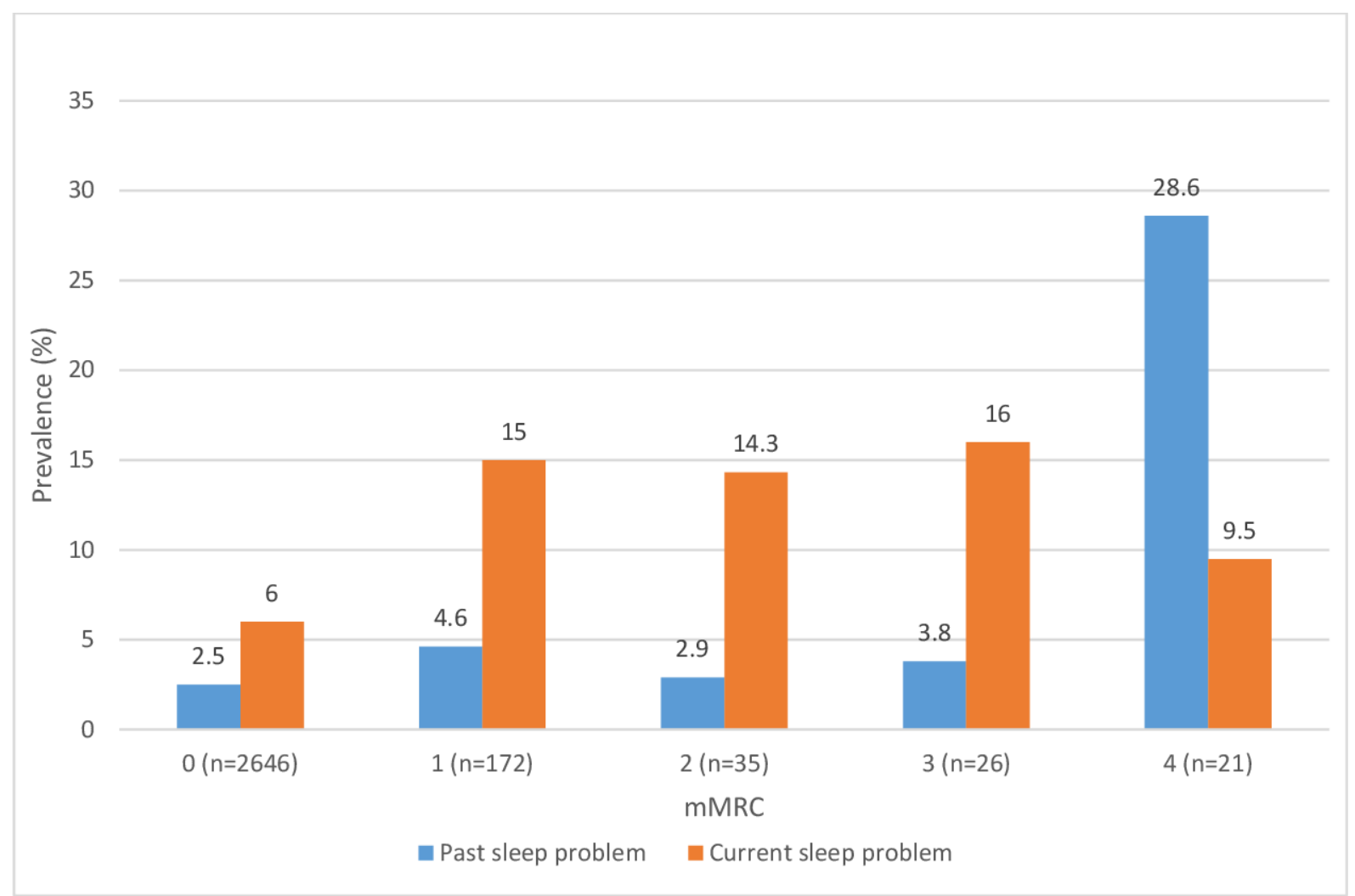

Figure 1 Prevalence of past and current sleep problems by level of chronic breathlessness in a random sample of the population of South Australia $(n=2898)$. mMRC, modified Medical Research Council breathlessness scale.

disturbance (measured with the PSQI) and poor quality of life (measured with Functional Assessment of Cancer Therapy-Lung. ${ }^{36}$ In another series of 115 people with lung cancer undergoing chemotherapy, sleep disturbance was strongly associated with poorer functional status and poorer cognition. ${ }^{40}$

\section{Strengths}

This is a survey of a random selection of the general population not limited by contact with health services. The dataset was standardised to a census-defined national population. The study builds on previous work defining rates of self-reported levels of exertion limited by breathlessness. ${ }^{31041}$ These rates are surprisingly stable across the population.

\section{Limitations}

There is an association between breathlessness and sleep problems, but the dynamics of this relationship (which comes first, which problem is dominant) cannot be defined from this study. Having found this strong signal, this will be the subject of future studies. More detailed clinical histories related to sleep are required as are laboratory sleep studies to understand the interaction between chronic breathlessness and specific sleep problems including insomnia. For example, the current study questions cannot distinguish between common sleep disorders such as insomnia and sleep apnoea. This preliminary exploration would strongly justify more in-depth population analyses comprising clinical and physiological data. The mMRC only provides a broad-brush picture of the level of exertion required before breathlessness supervenes. Multidimensional tools such as the Dyspnoea-12 or the Multidimensional Dyspnea Profile would allow a more detailed exploration of the aspects of breathlessness that most strongly impact insomnia and sleep disturbances. ${ }^{42}$ This preliminary study seeking to explore the relationship between sleep problems and chronic breathlessness in face-to-face interviews covering a very wide range of health topics has shown a relationship in univariate and multivariate analyses that now justifies progressing to a population study using validated tools for the assessment of sleep and chronic breathlessness. Validated and standardised tools such as the PSQI can now be justified in future study design and funding applications ${ }^{43}$ in order to reliably categorise individuals with sleep problems. Given that these are observational data, findings can only be interpreted as associations and not cause and effect. Future work could include seeking permission to contact respondents' treating clinicians or even extend to formal sleep studies for a subgroup of respondents that identify current sleep problems.

The relationship between the more severe levels of breathlessness and sleep problems is not statistically significant and almost certainly relates to the power achieved in the study because of low prevalence of severe and very severe breathlessness.

\section{Implications for future research}

Understanding whether people had long-term sleep problems and developed breathlessness with worsening 
COPD in later life, vice versa or a mixture of both will be important.

A before-and-after study of pulmonary rehabilitation in people with COPD demonstrated improvements in sleep quality measured on the PSQI and in breathlessness after 8 weeks of outpatient pulmonary rehabilitation. ${ }^{44}$ Such findings suggest that improving one symptom may have measurable collateral benefits with other long-standing symptoms. Future studies focusing on improving sleep may provide insights into better symptom control and the mechanisms of sleep disturbance.

Conversely, at least one double-blind, placebocontrolled crossover randomised trial has shown that when symptomatic breathlessness is reduced successfully, perceived sleep improves. ${ }^{45}$ This observation needs to be explored in a much larger study with individuals participating in the study for longer than the 8 days reported in the study by Martins et al. Such work should include formal sleep studies at least in a subgroup of participants.

\section{Implications for clinical care}

Notwithstanding the further research that needs to be done, these data suggest that clinicians should enquire about sleep health when they identify someone with chronic breathlessness and vice versa. This is especially the case for people with more severe chronic breathlessness.

Contributors DCC and MPE conceptualised the study and planned the data analysis and drafted the manuscript. DCC, MPE and DJE acquired the data, offered intellectual input and provided critical revision. SC performed the data analysis with input from DCC. All authors contributed to the drafts and approved the final version of the manuscript for publication.

Funding The authors have not declared a specific grant for this research from any funding agency in the public, commercial or not-for-profit sectors.

Competing interests None declared.

Patient consent for publication Not required.

Ethics approval The study was approved annually by the Human Research Ethics Committee of the South Australian Department of Health and the University of Adelaide Human Research Ethics Committee (H-097-2010). Informed verbal consent was obtained from each participant and continued participation accepted as ongoing consent. The study is reported in compliance with the Strengthening the Reporting of Observational Studies in Epidemiology checklist for cross-sectional studies.

Provenance and peer review Not commissioned; externally peer reviewed.

Data availability statement Data are available on reasonable request to bona fide researchers. Data are available on request to bona fide researchers.

Supplemental material This content has been supplied by the author(s). It has not been vetted by BMJ Publishing Group Limited (BMJ) and may not have been peer-reviewed. Any opinions or recommendations discussed are solely those of the author(s) and are not endorsed by BMJ. BMJ disclaims all liability and responsibility arising from any reliance placed on the content. Where the content includes any translated material, BMJ does not warrant the accuracy and reliability of the translations (including but not limited to local regulations, clinical guidelines, terminology, drug names and drug dosages), and is not responsible for any error and/or omissions arising from translation and adaptation or otherwise.

Open access This is an open access article distributed in accordance with the Creative Commons Attribution Non Commercial (CC BY-NC 4.0) license, which permits others to distribute, remix, adapt, build upon this work non-commercially, and license their derivative works on different terms, provided the original work is properly cited, appropriate credit is given, any changes made indicated, and the use is non-commercial. See: http://creativecommons.org/licenses/by-nc/4.0/.
ORCID iDs

David C Currow http://orcid.org/0000-0003-1988-1250

Diana Ferreira http://orcid.org/0000-0002-2554-8457

Danny J Eckert http://orcid.org/0000-0003-3503-2363

David Gonzalez-Chica http://orcid.org/0000-0002-7153-2878

Nigel Stocks http://orcid.org/0000-0002-9018-0361

\section{REFERENCES}

1 Frostad A, Soyseth V, Haldorsen T, et al. Respiratory symptoms and 30 year mortality from obstructive lung disease and pneumonia. Thorax 2006;61:951-6.

2 Voll-Aanerud M, Eagan TML, Wentzel-Larsen T, et al. Changes in respiratory symptoms and health-related quality of life. Chest 2007;131:1890-7.

3 Currow DC, Plummer JL, Crockett A, et al. A community population survey of prevalence and severity of dyspnea in adults. J Pain Symptom Manage 2009;38:533-45.

4 Currow DC, Dal Grande E, Ferreira D, et al. Chronic breathlessness associated with poorer physical and mental health-related quality of life (SF-12) across all adult age groups. Thorax 2017;72:1151-3.

5 Currow DC, Chang S, Reddel HK, et al. Breathlessness, anxiety, depression, and function-the BAD-F study: a cross-sectional and population prevalence study in adults. J Pain Symptom Manage 2020;59:197-205.

6 Ekström M, Johnson MJ, Taylor B, et al. Breathlessness and sexual activity in older adults: the Australian longitudinal study of ageing. NPJ Prim Care Respir Med 2018;28:20.

7 Marx G, Nasse M, Stanze H, et al. Meaning of living with severe chronic obstructive lung disease: a qualitative study. BMJ Open 2016;6:e011555.

8 Gysels M, Bausewein C, Higginson IJ. Experiences of breathlessness: a systematic review of the qualitative literature. Palliat Support Care 2007;5:281-302.

9 Nishimura K, Izumi T, Tsukino M, et al. Dyspnea is a better predictor of 5-year survival than airway obstruction in patients with COPD. Chest 2002;121:1434-40.

10 Smith AK, Currow DC, Abernethy AP, et al. Prevalence and outcomes of breathlessness in older adults: a national population study. $J \mathrm{Am}$ Geriatr Soc 2016;64:2035-41.

11 Currow DC, Smith J, Davidson PM, et al. Do the trajectories of dyspnea differ in prevalence and intensity by diagnosis at the end of life? a consecutive cohort study. J Pain Symptom Manage 2010;39:680-90.

12 Adams RJ, Appleton SL, Taylor AW, et al. Sleep health of Australian adults in 2016: results of the 2016 sleep health foundation national survey. Sleep Health 2017;3:35-42.

13 Roth T. Insomnia: definition, prevalence, etiology, and consequences. $J$ Clin Sleep Med 2007;3:S7-10.

14 Roth T, Coulouvrat C, Hajak G, et al. Prevalence and perceived health associated with insomnia based on DSM-IV-TR; international statistical classification of diseases and related health problems, tenth revision; and research diagnostic criteria/international classification of sleep disorders, second edition criteria: results from the America insomnia survey. Biol Psychiatry 2011;69:592-600.

15 Zhang $\mathrm{Y}$, Ren R, Lei F, et al. Worldwide and regional prevalence rates of co-occurrence of insomnia and insomnia symptoms with obstructive sleep apnea: a systematic review and meta-analysis. Sleep Med Rev 2019;45:1-17.

16 Bolge SC, Doan JF, Kannan H, et al. Association of insomnia with quality of life, work productivity, and activity impairment. Qual Life Res 2009;18:415-22.

17 Manber R, Chambers AS. Insomnia and depression: a multifaceted interplay. Curr Psychiatry Rep 2009;11:437-42.

18 Baglioni C, Battagliese G, Feige B, et al. Insomnia as a predictor of depression: a meta-analytic evaluation of longitudinal epidemiological studies. J Affect Disord 2011;135:10-19.

19 Taylor DJ, Lichstein KL, Durrence HH, et al. Epidemiology of insomnia, depression, and anxiety. Sleep 2005;28:1457-64.

20 Kling JM, Manson JE, Naughton MJ, et al. Association of sleep disturbance and sexual function in postmenopausal women. Menopause 2017;24:604-12.

21 Doghramji K. The epidemiology and diagnosis of insomnia. Am J Managed Care 2006;12:S214-20.

22 Taylor A, Dal Grande E, Wilson D. The South Australian health omnibus survey 15 years on: has public health benefited? Public Health Bull 2006;3:30-2.

23 Currow DC, Dal Grande E, Sidhu C, et al. The independent association of overweight and obesity with breathlessness in 
adults: a cross-sectional, population-based study. Eur Respir J 2017; $50: 1700558$

24 Australian Bureau of Statistics. Available: https://www.abs. gov.au/AUSSTATS/abs@.nsf/Latestproducts/3101.0Main\% 20Features3Sep\%202019?opendocument\&tabname=Summary\& prodno $=3101$.0\&iss [Accessed 22 Mar 2020].

25 Mahler DA, Wells CK. Evaluation of clinical methods for rating dyspnea. Chest 1988;93:580-6.

26 Bestall JC, Paul EA, Garrod R, et al. Usefulness of the medical research council (MRC) dyspnoea scale as a measure of disability in patients with chronic obstructive pulmonary disease. Thorax 1999;54:581-6.

27 Figarska SM, Boezen HM, Vonk JM. Dyspnea severity, changes in dyspnea status and mortality in the general population: the vlagtwedde/vlaardingen study. Eur J Epidemiol 2012;27:867-76.

28 Australian Bureau of Statistics. Socio-economic indexes for areas: finer levels of socio-economic summary measures, cat no.1352.0.55.135. Canberra, Australia, 2013.

29 World Health Organization. Obesity: preventing and managing the global epidemic. Report of a who consultation on obesity. Geneva, Switzerland: World Health Organization, 1997.

30 Grønseth R, Vollmer WM, Hardie JA, et al. Predictors of dyspnoea prevalence: results from the BOLD study. Eur Respir $J$ 2014;43:1610-20.

31 GEP B, Tidwell PW. Transformation of the independent variables. Technometrics 1962;4:531-50.

32 von Elm E, Altman DG, Egger M, et al. The strengthening the reporting of observational studies in epidemiology (STROBE) statement: guidelines for reporting observational studies. Int J Surg 2014;12:1495-9.

33 Johnson MJ, Bowden JA, Abernethy AP, et al. To what causes do people attribute their chronic breathlessness? a population survey. $J$ Palliat Med 2012;15:744-50.

34 Zeidler MR, Martin JL, Kleerup EC, et al. Sleep disruption as a predictor of quality of life among patients in the subpopulations and intermediate outcome measures in COPD study (SPIROMICS). Sleep 2018;41:zsy044.

35 Vardar-Yagli N, Saglam M, Savci S, et al. Impact of sleep quality on functional capacity, peripheral muscle strength and quality of life in patients with chronic obstructive pulmonary disease. Expert Rev Respir Med 2015;9:233-9.

36 Akinci B, Aslan GK, Kiyan E. Sleep quality and quality of life in patients with moderate to very severe chronic obstructive pulmonary disease. Clin Respir J 2018;12:1739-46.

$37 \mathrm{Lim}$ KE, Kim SR, Kim HK, et al. Symptom clusters and quality of life in subjects with COPD. Respir Care 2017;62:1203-11.

38 Lou VWQ, Chen EJ, Jian H, et al. Respiratory symptoms, sleep, and quality of life in patients with advanced lung cancer. J Pain Symptom Manage 2017;53:250-6.

39 Scharf SM, Maimon N, Simon-Tuval T. Sleep quality predicts quality of life in chronic obstructive pulmonary disease. Int J Chron Obstruct Pulmon Dis 2011;6:1-12.

40 Adetiloye AO, Erhabor GE, Obaseki DO, et al. Impact of sleep quality on the health-related quality of life of patients with chronic obstructive pulmonary disease. West Afr J Med 2018;35:173-9.

41 Bowden JA, To THM, Abernethy AP, et al. Predictors of chronic breathlessness: a large population study. BMC Public Health 2011;11:33

42 Yorke J, Moosavi SH, Shuldham C, et al. Quantification of dyspnoea using descriptors: development and initial testing of the Dyspnoea-12. Thorax 2010;65:21-6.

43 Buysse DJ, Reynolds CF, Monk TH, et al. The Pittsburgh sleep quality index: a new instrument for psychiatric practice and research Psychiatry Res 1989;28:193-213.

44 Soler X, Diaz-Piedra C, Ries AL. Pulmonary rehabilitation improves sleep quality in chronic lung disease. COPD 2013;10:156-63.

45 Martins RT, Currow DC, Abernethy AP, et al. Effects of low-dose morphine on perceived sleep quality in patients with refractory breathlessness: a hypothesis generating study. Respirology 2016;21:386-91. 